Philippe Meirieu y la pedagogía: un homenaje en Lyon. Páginas 119-122 en Revista de la Escuela de Ciencias de la EDUCACIÓN, AÑO12, NRO.11, VOL.1, ENERO A JUNIO DE 2016. ISSN 1851-6297. ISSN EN LINEA 2362-3349.

\title{
PHILIPPE MEIRIEU Y LA PEDAGOGÍA: UN HOMENAJE EN LYON
}

\author{
Alejandra Birgin* \\ Universidad de Buenos Aires y Universidad Pedagógica, Argentina. \\ alebirgin@hotmail.com
}

Recibido: 22/03/2016 Aceptado: 31/05/2016

\section{Resumen}

La siguiente reseña evoca una jornada de homenaje a Philippe Meirieu llevada a cabo en 2015 en la Universidad Lumière-Lyon 2 con motivo de su jubilación. Se sintetizan las palabras pronunciadas por investigadores, profesores y militantes que señalan algunos de los principales aportes que Philippe Meirieu ha realizado a los debates pedagógicos de las últimas décadas, con especial énfasis en la fuerte inscripción de sus ideas en las particularidades del debate francés, la diversidad de formas y modalidades de su compromiso militante y la relación entre su producción y la complejidad sociocultural contemporánea.

\section{Palabras clave:}

Philippe Meirieu - Pedagogía - Transmisión - Autoridad - Compromiso Público.

\section{Abstract}

The following review evokes a day of tribute and farewell to Philippe Meirieu held on 10th January 2015 at the Lumière-Lyon 2 University on the occasion of his retirement. Words spoken by researchers, professors and activists referring to some of the major contributions Philippe Meirieu has made to the educational debates of recent decades are synthesized, with special emphasis on the inscription of his ideas on the French discussions, the diversity of forms and modalities of his militant commitment and the relationship between his production and the contemporary sociocultural complexity.

\section{Keywords}

Philippe Meirieu - Pedagogy - Transmission - Authority - Public commitment.

* Profesora e investigadora de la Universidad de Buenos Aires y de la Universidad Pedagógica, Argentina. 
Revista de la Escuela de Ciencias de la Educación, año12, nRo. 11, vol. 1, enero a Junio de 2016. PÁginas 119-122. ISSN 1851-6297. ISSN en línea 2362-3349. Philippe Meirieu y LA Pedagogía: un homenaje en Lyon. AlejandRa Birgin

El 10 de enero de 2015 se realizó en la Universidad Lumière-Lyon 2 una jornada de homenaje y despedida a Philippe Meirieu (en adelante, PM) que dejaba su actividad de profesor e investigador porque se jubilaba. La jornada se llamó “¿Hacia dónde van los pedagogos? Miradas y perspectivas a partir de la obra de Philippe Meirieu" y contó con profesores de universidades, docentes de escuelas, militantes pedagógicos y sindicalistas, diversidad que es parte de la amplitud de interlocutores y de espacios con los que PM dialoga. La Jornada incluyó testimonios de vida con reflexiones teóricas rigurosas y con aportes militantes.

Todo el evento estuvo atravesado por la conmoción que produjo el atentado del 7 de enero, que asesinó a gran parte del equipo periodístico de la revista Charlie Hebdo. Varias ponencias remitieron a la dolorosa y compleja situación, así como al lugar que le cabe a la escuela y a la educación en ella.

Luego del reconocimiento a la obra de PM por parte de las autoridades de la Universidad, del Instituto de Ciencias y Prácticas de la Educación y la Formación - ISPEF- y del Doctorado en Educación, la conferencia introductoria estuvo a cargo de Daniel Hameline, profesor honorario de la Universidad de Ginebra, quien la planteó alrededor de tres metáforas "El recinto, el límite y la explanada" para mostrar con ellas los lugares y la potencia de un pedagogo en acción. El investigador en educación, dijo Hameline, se hace pedagogo cuando sale del recinto, trasciende los límites y responde a una convicción: el pensamiento sobre lo humano. Ese es, desde su perspectiva, PM.

Guy Avanzini, a quien PM reconoce como uno de sus maestros, relató que en los 70 desde la Universidad realizaban un trabajo de investigación con directores y profesores de colegios de la región. Allí conoció a PM quien trabajaba como profesor de secundaria. Fue a partir de lo que PM desarrollaba en su práctica escolar que Avanzini le propuso que lo transforme en una tesis doctoral. "PM inicia así una sistematización académica de su experiencia profesional que deviene en tesis e ingresa a la Universidad como investigador y docente". Agrega Avanzini: "PM muestra con su tesis y su recorrido posterior una articulación posible entre militantismo y reflexión exigente".

Entre muy breves y deliciosas intervenciones musicales del Centro de Formación de Músicos de Lyon, se sucedieron las ponencias de François Jarraud (responsable de Café pédagogique), Osthiane Mathon (maestra y militante pedagógica, que definió a PM como un constante "cortocircuitador"), de Luc Cédelle (periodista de Le Monde que hizo en 2012 un libro de entrevistas a Meirieu: Un pédagogue dans la Cité) y de Bernard Rey de la Universidad Libre de Bruselas, Charles Hadji de la Universidad de Grenoble y Mireille Cifali de la Universidad de Ginebra.

Tres tópicos atravesaron el conjunto de las presentaciones: la fuerte inscripción de las ideas de PM en las particularidades del debate francés, la 
Revista de la Escuela de Ciencias de la Educación, año 12, nRo.11, vol. 1, enero a Junio de 2016. PÁginas 119-122. ISSN 1851-6297. ISSN en línea 2362-3349. Philippe MeIRIeu y LA Pedagogía: un homenaje en Lyon. AlejandRa Birgin

diversidad de formas y modalidades de su compromiso militante y la relación entre su producción y la complejidad sociocultural contemporánea.

Respecto de la inscripción de PM en el debate francés, las diferentes intervenciones se centraron en su sensibilidad hacia las problemáticas concretas de la escuela y un problema recurrente en la agenda pública, la cuestión de la autoridad y la pedagogía. PM discute con algunas posiciones intelectuales que, basadas en la tradición de la Academia y la Enciclopedia francesa, definen a los pedagogos como aquellos que rechazan la autoridad de la cultura, del maestro, del Estado, abandonando la exigencia y la autoridad educativa. Desde esa posición, entienden que en "la situación catastrófica" del sistema escolar actual los pedagogos tienen una severa responsabilidad porque su obstinación pedagógica por transmitir la cultura pondría en juego métodos que comprometen gravemente su preservación (Cady, 2006; Birgin, 2011). PM sostiene, en cambio, que esa posición proviene de subestimar que, para que la enseñanza ocurra, es necesario crear (en distintos planos y escalas) condiciones que posibilitan la transmisión. De eso se trata la pedagogía.

Respecto de su compromiso público con la enseñanza, se señaló la participación comprometida de PM en distintas instancias e instituciones: dirigió un canal de Televisión Educativa (CAPCanal), participó activamente en la prensa escrita, se involucró en los debates entre docentes y pedagogos, dirigió el INRP de Francia (1) y el IUFM de Lyon (2), etc. En particular, se señaló su disponibilidad permanente y desprejuiciada a sumarse a espacios diversos de discusión y militancia. Se destacó que ha publicado más de 40 libros en al menos diez idiomas y que algunos tienen múltiples reediciones en Francia, como Apprendre oui, mais comment (3) que data de 1987 y va por su $25^{a}$ edición.

Como señala Daniel Hameline: "La obra de PM ilustra de manera brillante, en la segunda mitad del siglo XX, los aportes ofrecidos, pero también los riesgos (hasta quizás los caminos sin salida) de un pensamiento cuando, de manera deliberada, se lo quiere "pedagógico". Mantenerse en la brecha entre la "cuidad sabia" y la "ciudad mundana" (como lo señala Bourdieu) es arriesgarse a no ser escuchado ni por las poblaciones de la una, ni de la otra. La pedagogía encuentra en esta postura "entre dos" uno de los lugares de sus debates endémicos. Específicamente, la obra de PM se expone allí a polémicas, a veces cruzadas, cuya violencia revela el valor del lugar que ocupa y la manera singular que tiene Meirieu de habitarla".

En cuanto a los desafíos actuales, se señaló cómo la pedagogía que construye PM se inscribe en la trama social contemporánea, promoviendo el pensar el trastrocamiento de los escenarios de la transmisión que producen las transformaciones de este tiempo, revisando sus límites y fronteras, sin dejar de invocar una y otra vez la historia de la pedagogía. Su optimismo no es ingenuo: relativiza oposiciones binarias, reconoce tensiones y paradojas (transmisión y 
Revista de la Escuela de Ciencias de la Educación, año 12, nRo. 11, vol. 1, enero a Junio de 2016. Páginas 119-122. ISSN 1851-6297. ISSN en línea 2362-3349. PhilipPe MeIRIEU y LA PEdagogía: un hOMENAJe en Lyon. AlejandRa Birgin

emancipación, responsabilidad y libertad, espacios de seguridad y de osadía) y asume el riesgo de la intervención en tiempo presente.

El homenaje a Philippe Meirieu fue muy emotivo, cálido, entusiasta. Él estaba sentado en la primera fila, fuertemente conmovido, seguramente atento al reclamo insistente "No te vas". Es que aquí y allá y en tantos otros lugares la conversación con PM no se jubila.

\section{Notas Bibliográficas}

(1) Instituto Nacional de Investigaciones Pedagógicas

(2) Instituto Universitario de Formación de Docentes

(3) En castellano: Meirieu, P. (1992). Aprender, sí. Pero ¿cómo? Barcelona: Octaedro.

\section{Referencias Bibliográficas}

- Birgin, A. (2011). Entrevista a Philippe Meirieu. Revista del Instituto de Investigaciones en Ciencias de la Educación, 30, 5-16. Recuperado de http://revistascientificas.filo.uba.ar/ index.php/iice/article/view/141

- Cady, A. (2006). Les discours des « républicains anti-pédagogues » (1983-2003): étude critique d'une argumentation et de ses présupposés. (Tesis de doctorado). Universidad de Nantes, Nantes. Francia. 